\title{
A GCM study of organic matter in marine aerosol and its potential contribution to cloud drop activation
}

\author{
G. J. Roelofs \\ Institute for Marine and Atmospheric Research Utrecht (IMAU), Utrecht University, Utrecht, The Netherlands
}

Received: 13 April 2007 - Published in Atmos. Chem. Phys. Discuss.: 27 April 2007

Revised: 3 January 2008 - Accepted: 10 January 2008 - Published: 13 February 2008

\begin{abstract}
With the global aerosol-climate model ECHAM5HAM we investigate the potential influence of organic aerosol originating from the ocean on aerosol mass and chemical composition and the droplet concentration and size of marine clouds. We present sensitivity simulations in which the uptake of organic matter in the marine aerosol is prescribed for each aerosol mode with varying organic mass and mixing state, and with a geographical distribution and seasonality similar to the oceanic emission of dimethyl sulfide. Measurements of aerosol mass, aerosol chemical composition and cloud drop effective radius are used to assess the representativity of the model initializations. Good agreement with the measurements is obtained when organic matter is added to the Aitken, accumulation and coarse modes simultaneously. Representing marine organics in the model leads to higher cloud drop number concentrations and thus smaller cloud drop effective radii, and this improves the agreement with measurements. The mixing state of the organics and the other aerosol matter, i.e. internal or external depending on the formation process of aerosol organics, is an important factor for this. We estimate that globally about $75 \mathrm{Tg} \mathrm{C} \mathrm{yr}^{-1}$ of organic matter from marine origin enters the aerosol phase, with comparable contributions from primary emissions and secondary organic aerosol formation.
\end{abstract}

\section{Introduction}

Aerosol particles influence optical characteristics and the lifetime of clouds through the so-called first and second aerosol indirect effects (e.g. Lohmann and Feichter, 2005). Anthropogenic activities have caused an increase of the atmospheric burden of aerosol and aerosol precursors com-

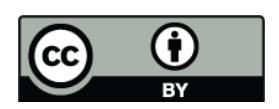

Correspondence to: G. J. Roelofs (roelofs@phys.uu.nl) pared to the pre-industrial atmosphere, and this may have altered regional and global radiative cloud forcings (e.g. Penner et al., 2001). The large spatial and temporal variability in size, chemical composition, and hygroscopicity of particles impede accurate estimation of the aerosol direct and indirect forcing (Textor et al., 2006). Poor understanding of aerosol effects leads to large uncertainties in assessing the sensitivity of climate to human perturbations and in projections of climate change (Andreae et al., 2005).

An accurate quantification of the climate forcing from anthropogenic aerosol requires detailed knowledge of natural aerosol as well. Estimates of the amount of organic aerosol matter produced from vegetation emissions are highly uncertain associated with the chemical properties and emission strength of precursor gases, gas- and aqueous phase oxidation pathways and yield of reaction products, formation of secondary organic aerosol (SOA) through condensation of semi-volatile gases and the size distribution of the organic matter (e.g. Jacobson et al., 2000; Kanakidou et al., 2005). Other aerosol components also play a role. Kulmala et al. (2000) mention that thermodynamically stable clusters formed in the atmosphere, for example of $\mathrm{H}_{2} \mathrm{SO}_{4}-\mathrm{NH}_{3}-\mathrm{H}_{2} \mathrm{O}$, can undergo rapid growth to nucleation mode sizes and larger when mixed with air containing condensable organic gases. Current estimates of SOA production from continental vegetation display a large range, between $12-70 \mathrm{Tg} \mathrm{SOA} / \mathrm{yr}$ from bottom-up approaches (Kanakidou et al., 2005) and 200$800 \mathrm{Tg} \mathrm{C} / \mathrm{yr}$ from top-down approaches (Goldstein and Galbally, 2007).

Several decades ago Berg and Winchester (1978) reported studies that found a strong chemical similarity between sea surface organic material and airborne organics, and that indicated that aerosol with relatively high organic aerosol content is associated with air masses that passed over ocean regions rich in organic material. It was concluded that the ocean must be an important source of the organic constituents in marine air, with the quantity of organic carbon in seawater, the

Published by Copernicus Publications on behalf of the European Geosciences Union. 
amount of surfactants in seawater and the chemical and physical nature of oceanic organic compounds as important governing factors (Hoffman and Duce, 1976). Later, scientific attention switched to the anthropogenic aerosol burden in remote regions, and studies on marine aerosol organics were often directed at DMS and the uptake of MSA in aerosol (Fitzgerald, 1991; O’Dowd et al., 1997; Heintzenberg et al., 2000).

Recent measurements in Mace Head (Ireland) showed the presence of relatively large quantities of aerosol organics, $\sim 620 \mathrm{ng} / \mathrm{m}^{3}$ in summer, in air masses advected from remote marine regions (O'Dowd et al., 2004). The nature of the organic species indicated a primary marine source involving bubble-bursting processes during phytoplankton blooms (Cavalli et al., 2004). Secondary aerosol formation, possibly involving isoprene, also affects marine aerosol. Isoprene emissions from the ocean surface were reported by Yokouchi et al. (1999) and Sinha et al. (2007), with phytoplankton as a likely source (Shaw et al., 2003). Claeys et al. (2004) showed that the oxidation of isoprene produces water-soluble methyl tetrols, implying potential influence of isoprene on cloud drop activation. Meshkidze and Nenes (2006) found a correlation between the seasonal variation of cloud drop effective radius and phytoplankton blooms in the southern Atlantic Ocean region, and linked this to isoprene production by plankton.

Aerosol organics that originate from the ocean contribute to the natural atmospheric aerosol burden. The radiative properties of the natural atmosphere form the background against which the impact of anthropogenic activities on the Earth's energy budget is compared. Current estimates indicate on average that the anthropogenic aerosol indirect forcing over the ocean is $75 \%$ of that over land, with several studies estimating a larger forcing over the ocean than over land (see Lohmann and Feichter, 2005, their Fig. 3; Lohmann and Lesins, 2002). However, these studies did not take the marine organic emissions and their effect on aerosol and cloud properties into account.

When emissions of aerosol and aerosol precursors are not fully accounted for in aerosol-climate modeling, cloud drop concentrations will be underestimated. In a previous model study with the aerosol-climate model ECHAM5-HAM, including a parameterization for cloud drop activation and sizedependent aqueous phase sulfur chemistry, that considered only ocean emissions of sea salt and DMS, simulated effective radii $\left(R_{\text {eff }}\right)$ over the continents were of the same order as observed whereas $R_{\text {eff }}$ in marine clouds exceeded observations from ISCCP (International Satellite Cloud Climatology Project) by about $5 \mu \mathrm{m}$ in the Northern Hemisphere $(\mathrm{NH})$ and $6 \mu \mathrm{m}$ in the Southern Hemisphere (SH) (Roelofs et al., 2006). This is equivalent with an underestimation of the cloud drop number concentration (CDNC) by a factor of 3 or 4. Although inaccuracies in simulated updraft velocities, aerosol transports and cloud drop activation may contribute to this discrepancy, marine CDNC was found to be limited mainly by particle concentrations in the coarse and accumulation modes, which are smaller than observed (Stier et al., 2005). The discrepancy may partly be due to errors in the emission and size distribution of sea salt. In this study, however, we investigate to what extent and in what amount aerosol organics of marine origin may be responsible for the discrepancies, while accounting for the influence of the mixing state and the size distribution of the organics. To this purpose we apply a top-down approach in which specific amounts of organic matter are directly added to different aerosol modes. Observations of aerosol composition and cloud drop radius are used as a constraint to assess the representativity of the marine organic emissions applied in the model. Section 2 describes the aerosol-climate model ECHAM5-HAM and the cloud processing parameterization. Section 3 introduces the measurements of the aerosol chemical composition that will be used to assess the model representativity, and the emission scenarios applied in the sensitivity simulations. Section 4 presents the results of the sensitivity simulations, and Sect. 5 summarizes and discusses the results.

\section{Model description}

The study is performed with a version of the coupled aerosolclimate model ECHAM5-HAM similar to the one applied by Stier et al. (2005). ECHAM5-HAM consists of the general circulation model ECHAM version 5 and an aerosol module (HAM). The model uses 19 vertical layers in a hybrid $\sigma$-p-coordinate system, from the surface to $10 \mathrm{hPa}$. HAM accounts for emissions of aerosol and aerosol precursors, chemical transformations, nucleation of new particles and condensation of semi-volatile $\mathrm{H}_{2} \mathrm{SO}_{4}$ on existing particles, coalescence between particles and dry and wet deposition. The core of HAM is the aerosol dynamical module M7 (Vignati et al., 2004; Wilson et al., 2001). M7 describes the aerosol population with four soluble and three insoluble aerosol modes composed of (mixtures of) sulfate, organic carbon, black carbon, sea salt and dust. The modes are lognormal and each mode is characterized by the particle number concentration and mass of associated aerosol components, from which an average dry particle radius is derived. The size ranges considered are below $0.005 \mu \mathrm{m}$ particle radius for the nucleation mode, between 0.005 and $0.05 \mu \mathrm{m}$ particle radius for the Aitken mode, between 0.05 and $0.5 \mu \mathrm{m}$ particle radius for the accumulation mode, and above $0.5 \mu \mathrm{m}$ particle radius for the coarse mode. All emissions are treated as primary emissions except for the sulfur compounds. Hence, secondary organic aerosol (SOA) formation associated with organic emissions from vegetation and - in this study - from the ocean surface is not calculated explicitly. Instead, organics are emitted from the surface as primary particles. For further information on emissions 
considered in the model we refer to Stier et al. (2005) and Roelofs et al. (2006).

The bulk cloud chemistry scheme in ECHAM5-HAM has been replaced with a cloud processing parameterization. This parameterization is an excellent tool for this study because it contains consistent and size-dependent representations of aerosol activation and in-cloud sulfate chemistry. First, the maximum supersaturation at the cloud base is estimated through an empirical approach derived from cloud parcel model simulations (Hänel, 1987) as described in more detail in Roelofs et al. (2006). The activation parameterization performs relatively accurately, i.e. the predicted supersaturation and CDNC are generally within $30 \%$ of cloud parcel model results, which is considerably smaller than the discrepancy between simulated and observed CDNC, a factor of 3 to 4 . The second step in the parameterization calculates aqueous phase formation of sulfate and its distribution over the different activated modes, i.e. the modes that contribute to CDNC. The parameterization is linked to the climate model's largescale cloud scheme (Lohmann and Roeckner, 1996). In this study the simulated meteorology is generated by the climate model and does not reflect actual meteorological events. The computed cloud drop concentration does not feed back on large-scale cloud evolution and precipitation formation in order to eliminate meteorological effects in comparing the sensitivity simulations.

\section{Description of the sensitivity studies}

The measurements of O'Dowd et al. (2004) of the organic fraction in marine aerosol sampled in Mace Head can be summarized as follows. The organic mass in the fine aerosol modes displays a significant seasonality with $\sim 620 \mathrm{ng} / \mathrm{m}^{3}$ in summer and $70 \mathrm{ng} / \mathrm{m}^{3}$ in winter (see also Yoon et al., 2007). In this study we focus on the summer months June, July and August (JJA) when the total observed particulate organic mass is about ten times larger than in winter. Further, in winter the organic mass associated with the Aitken mode was below the detection limit. Measured organic mass fractions in summer were $83 \%$ for particles smaller than $0.125 \mu \mathrm{m}$ diameter (comparable with the Aitken mode in ECHAM5-HAM), $65 \%$ for particles with a diameter between 0.125 and $1 \mu \mathrm{m}$ (the accumulation mode in ECHAM5-HAM), and $~ 3 \%$ in particles with diameters exceeding $1 \mu \mathrm{m}$ (the coarse mode in ECHAM5-HAM). The approximate mass fractions of nsssulfate in the Aitken and accumulation modes are $12 \%$ and $25 \%$, respectively. Since the measurements were performed on air samples advected from remote marine regions it can be assumed that the aerosol sulfate mainly originates from oxidation of DMS.

In view of the observed ratio between organic and sulfate masses and the model global DMS source of $\sim 23 \mathrm{Tg} \mathrm{S} / \mathrm{yr}$ (Stier et al., 2005) we assume a global production of marine organic aerosol varying between $25 \mathrm{Tg} \mathrm{C} / \mathrm{yr}$ and $75 \mathrm{Tg}$
$\mathrm{C} / \mathrm{yr}$ in the sensitivity simulations. Given the relation between phytoplankton and ocean surface emissions of primary organic particles (Cavalli et al., 2004), isoprene and DMS (Sinha et al., 2007), the seasonality of the marine organic emissions is assumed to follow the emission of DMS. The molar weight of oxalic acid is taken to be representative for the organic matter, and the organics are distributed evenly over the soluble and insoluble aerosol modes. The organics in the soluble aerosol are assumed to have a soluble fraction of $50 \%$. Overall, the initialization is in agreement with the measured soluble fraction of $\sim 25 \%$. Note that for relatively soluble organics a $25 \%$ change of the solubility has a modest influence on the average CDNC (Roelofs et al., 2006). This is in agreement with the findings of Ducek et al. (2006) that the size distribution of the aerosol by itself explains $\sim 90 \%$ of the variation in cloud condensation nucleus (CCN) concentrations while the particle chemical composition plays a secondary role.

Each sensitivity simulation is run for four years in the $\mathrm{T} 21$ resolution (approximately $5.6^{\circ} \times 5.6^{\circ}$ with a 2400 -s time step). The relatively coarse resolution may affect the simulated CDNC to some extent. Previous studies show that simulated transport patterns are more representative at a higher resolution (e.g. T42, T63) (e.g. Kentarchos et al., 2000). On the other hand, the use of a rather coarse resolution in this study enables a detailed sensitivity analysis with varying mass, size distribution and mixing state of the organics.

Table 1 presents the marine organic aerosol amounts in the sensitivity simulations. Organic aerosol matter from the ocean surface is deposited in the Aitken (labeled K), accumulation (labeled A) or coarse mode (labeled C), or a combination of these. The mixing state of the marine organics in the aerosol phase may have a significant effect on the cloud forming properties of the aerosol (O'Dowd et al., 2004). Therefore we apply different mixing states: external (labeled $e$ or $x$, in $x$ the organic mass is distributed over four times as many particles as represented in $e$ ) or internal (labeled $i$ ), which reflect different aerosol formation mechanisms. Important processes for SOA formation are condensation of semi-volatile organics leading to new particle formation (external mixture) or growth of existing particles (internal mixture) (Kanakidou et al., 2005). Organics may also enter the atmosphere through mechanical forces, i.e. wind-driven generation of particles out of the organic mono-layer (external mixture) or of sea-salt mixed with organics (internal mixture) (Berg and Winchester, 1978; Cavalli et al., 2004). Other processes that affect the aerosol mixing state, such as condensation of sulfuric acid, coagulation between particles and cloud processing, are explicitly represented in ECHAM5-HAM. 
Table 1. Simulations performed in this study.

\begin{tabular}{|c|c|}
\hline simulation $*$ & description \\
\hline CTRL & $\begin{array}{l}\text { The control simulation without ocean or- } \\
\text { ganic emissions }\end{array}$ \\
\hline$A i$ & $\begin{array}{l}\text { Emission of } 25 \mathrm{Tg} \mathrm{C} / \mathrm{yr} \text { globally, internally } \\
\text { mixed in the accumulation mode }\end{array}$ \\
\hline$A e$ & $\begin{array}{l}\text { Emission of } 25 \mathrm{Tg} \mathrm{C} / \mathrm{yr} \text { globally, externally } \\
\text { mixed in the accumulation mode with a par- } \\
\text { ticle mass of } 6 \times 10^{-18} \mathrm{~kg}\end{array}$ \\
\hline$A x$ & $\begin{array}{l}\text { As Ae but with a particle mass of } \\
1.5 \times 10^{-18} \mathrm{~kg}\end{array}$ \\
\hline Ke & $\begin{array}{l}\text { Emission of } 25 \mathrm{Tg} \mathrm{C} / \mathrm{yr} \text { globally, externally } \\
\text { mixed in the Aitken mode with a particle } \\
\text { mass of } 6 \times 10^{-19} \mathrm{~kg}\end{array}$ \\
\hline$K e A i$ & $\begin{array}{l}\text { Emission of } 50 \mathrm{Tg} \mathrm{C} / \mathrm{yr} \text { globally, } \mathrm{Ke} \text { and } A i \\
\text { combined }\end{array}$ \\
\hline $\mathrm{KeAe}$ & $\begin{array}{l}\text { Emission of } 50 \mathrm{Tg} \mathrm{C} / \mathrm{yr} \text { globally, } \mathrm{Ke} \text { and } \mathrm{Ae} \\
\text { combined }\end{array}$ \\
\hline $\operatorname{KeAx}$ & $\begin{array}{l}\text { Emission of } 50 \mathrm{Tg} \mathrm{C} / \mathrm{yr} \text { globally, } \mathrm{Ke} \text { and } A x \\
\text { combined }\end{array}$ \\
\hline$K x$ & $\begin{array}{l}\text { As Ke but with a particle mass of } \\
1.5 \times 10^{-19} \mathrm{~kg}\end{array}$ \\
\hline$K x A i$ & $\begin{array}{l}\text { Emission of } 50 \mathrm{Tg} \mathrm{C} / \mathrm{yr} \text { globally, } K x \text { and } A e \\
\text { combined }\end{array}$ \\
\hline KxAe & $\begin{array}{l}\text { Emission of } 50 \mathrm{Tg} \mathrm{C} / \mathrm{yr} \text { globally, } K x \text { and Ae } \\
\text { combined }\end{array}$ \\
\hline$K x A x$ & $\begin{array}{l}\text { Emission of } 50 \mathrm{Tg} \mathrm{C} / \mathrm{yr} \text { globally, } K x \text { and } A x \\
\text { combined }\end{array}$ \\
\hline$K e 2$ & $\begin{array}{l}\text { Emission of } 50 \mathrm{Tg} \mathrm{C} / \mathrm{yr} \text { globally, externally } \\
\text { mixed in the Aitken mode with a particle } \\
\text { mass of } 6 \times 10^{-19} \mathrm{~kg}\end{array}$ \\
\hline $\mathrm{KeAiCi}$ & $\begin{array}{l}\text { As } K e A i \text { with additional emission of } 25 \mathrm{Tg} \\
\mathrm{C} / \mathrm{yr} \text { globally, internally mixed in the coarse } \\
\text { mode }\end{array}$ \\
\hline
\end{tabular}

* $K, A$ and $C$ refer to the Aitken accumulation and coarse mode, respectively. Character $i$ refers to aerosol with internally mixed organics, and $e$ and $x$ refer to aerosol with externally mixed organics. New particles formed in $x$ contain $25 \%$ of the particulate mass considered in $e$ while four times as many particles are formed.

\section{Results}

\subsection{Aerosol mass and composition}

In this section we compare the simulated aerosol mass and composition in the surface layer in the region $16^{\circ} \mathrm{W}-11^{\circ} \mathrm{W}$, $50^{\circ} \mathrm{N}-55^{\circ} \mathrm{N}$, i.e. over the ocean west of Ireland, with the measurements of O'Dowd et al. (2004). Simulated particle number concentrations for the Aitken and accumulation modes and averaged over JJA are shown in Fig. 1. Figure 2 shows the simulated modal aerosol mass and chemical composition averaged over JJA, and the observed values (labeled $O B S$ ) derived from O'Dowd et al. (2004). Since ammonia is not considered explicitly in the model we assume that
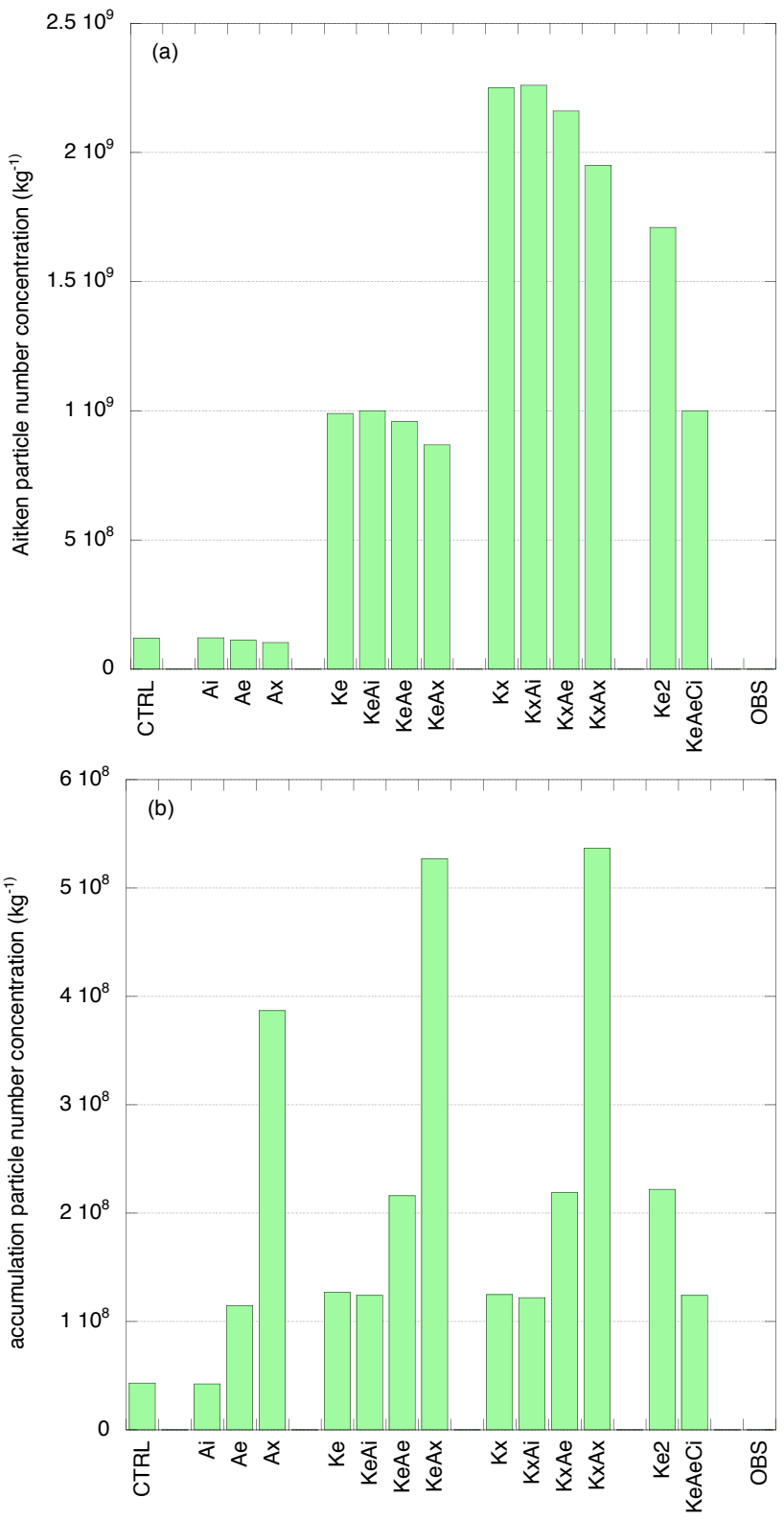

Fig. 1. Simulated particle concentrations $\left(\mathrm{kg}^{-1}\right)$ averaged over June, July, August for (a) the Aitken mode and (b) the accumulation mode.

the simulated and observed sulfate is present as ammonium bisulfate. The mass fractions of the individual aerosol components in $O B S$ may therefore differ slightly from O'Dowd et al. (2004). Figure 2 shows that the organic mass in the Aitken and accumulation modes in the base case simulation CTRL is underestimated compared to the observations, and the sulfate mass in the Aitken mode is also smaller than observed. 


\subsubsection{Ai, Ae, Ax}

In these simulations a global amount of $\sim 25 \mathrm{Tg} \mathrm{C} / \mathrm{yr}$ of organics is added to the accumulation mode. The accumulation mode particle concentration in the simulation with internally mixed organics, Ai, is about the same as in CTRL (Fig. 1b). Number concentrations are larger when the organics are mixed externally $(A e, A x)$, and in all three simulations the organic mass in the accumulation mode is larger than in CTRL. The total accumulation mode mass is largest in $A x$ and smallest in $A i$, which reflects the size dependence of removal processes. The Aitken mode is not affected much by the additional organic matter in the accumulation mode.

\subsubsection{Ke, KeAi, KeAe, KeAx}

In Ke a global amount of $\sim 25 \mathrm{Tg} \mathrm{C} / \mathrm{yr}$ of organics is added to the Aitken mode. Putting the organics into the Aitken mode in an externally mixed state results in a higher number concentration (Fig. 1a) and mass (Fig. 2a) for this mode. The Aitken mode mass in $\mathrm{Ke}$ is close to observed. The organics are transferred from the Aitken to the accumulation mode through impaction or cloud processing, resulting in a larger accumulation mode mass and number concentration than in CTRL (Figs. 1b, 2b), albeit smaller than observed. $\mathrm{Ke} 2$ is similar to $\mathrm{Ke}$ but twice the organic mass is added to the Aitken mode. $\mathrm{Ke} 2$ overestimates the Aitken organic mass compared to the observations but now the accumulation mode organic mass agrees better. We note that simulated sulfate in the Aitken mode is also larger than in CTRL. Due to the additional organic aerosol matter the total surface of the Aitken particles is larger, thus enabling more efficient condensation of sulfuric acid, while particles may also be subject to cloud processing and in-cloud sulfate formation (see also Roelofs et al., 2006; Kerminen, 2001).

In $K e A i, K e A e$ and $K e A x$ organic matter is added to the Aitken mode as in $K e$, and the same amount is added to the accumulation mode as external or internal mixture. Comparison of the results for these simulations with $\mathrm{Ke}$ yields a qualitatively similar picture as the comparison of $A i, A e$ and $A x$ with CTRL presented above. Now, however, the simulated accumulation mode mass is of the same order as observed (with KeAi somewhat smaller and KeAx somewhat larger; Fig. 2b), while also the simulated relative mass fractions (organics: $\sim 50 \%$, ammonium bisulfate: $\sim 20 \%$, sea salt: $\sim 30 \%)$ agree better with the measurements.

\subsubsection{Kx, KxAi, KxAe, KxAx}

In $K x$ a global amount of $\sim 25 \mathrm{Tg} \mathrm{C} / \mathrm{yr}$ of organics is added to the Aitken mode but it is distributed over four times the amount of particles compared to Ke. The computed Aitken particle number concentration is therefore larger. Simulated organic and sulfate masses in this mode are also larger, possibly reflecting a longer atmospheric lifetime for smaller par-
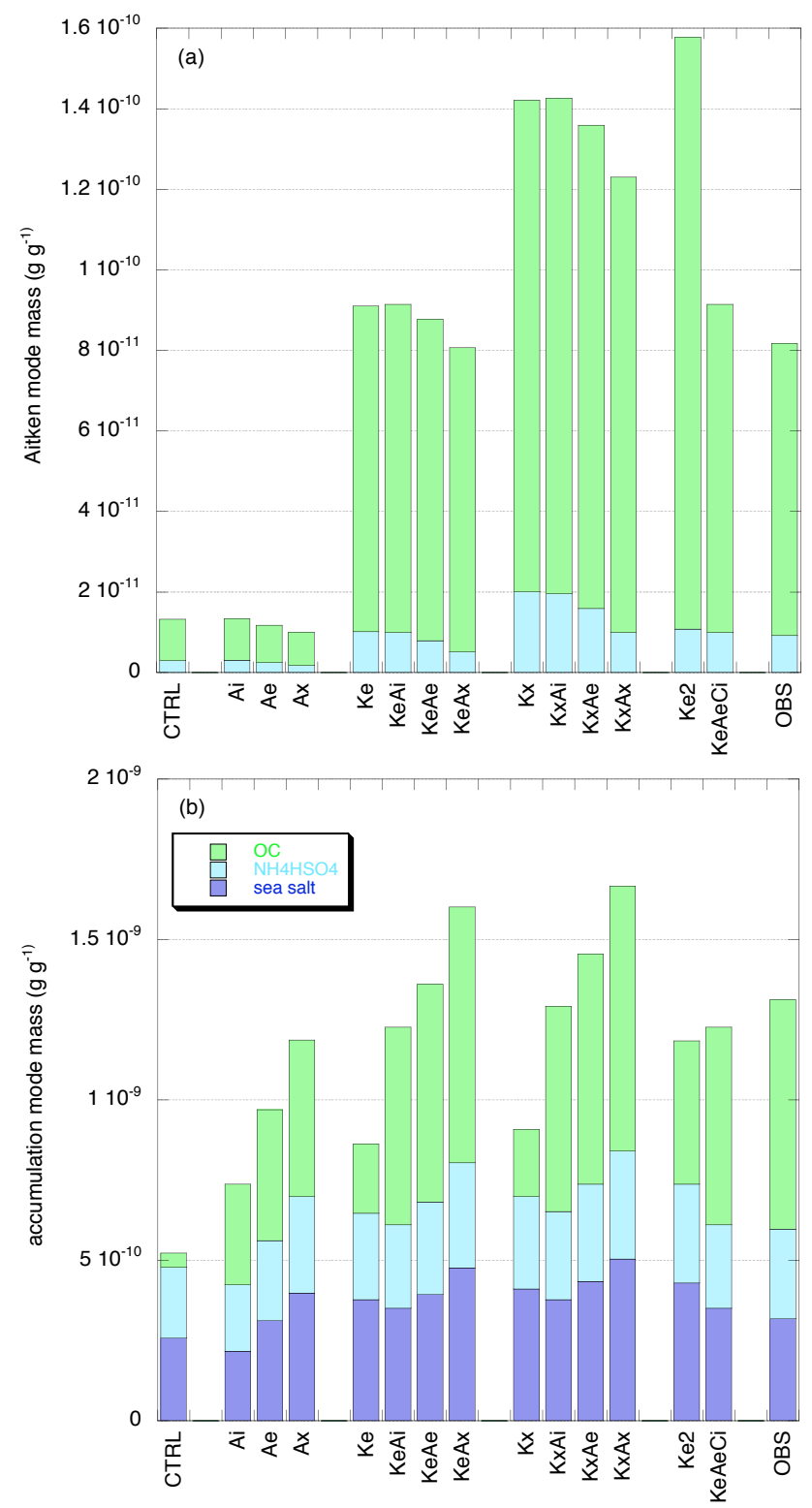

Fig. 2. Simulated aerosol mass and chemical composition $\left(\mathrm{g} \mathrm{g}^{-1}\right)$ averaged over June, July, August for (a) the Aitken mode and (b) the accumulation mode.

ticle sizes. The relative differences in accumulation mode mass and concentration between these simulations are comparable to the differences between $K e, K e A i, K e A e$ and $K e A x$, or CTRL, $A i, A e$ and $A x$ discussed previously.

Based on the results presented thus far it can be concluded that the best agreement between the modelled and observed Aitken and accumulation mode mass and chemical composition is obtained when organics emitted from the ocean surface enter the aerosol phase through both modes. Model results indicate that this involves new particle formation due to condensation of semi-volatile gases for the Aitken mode, 

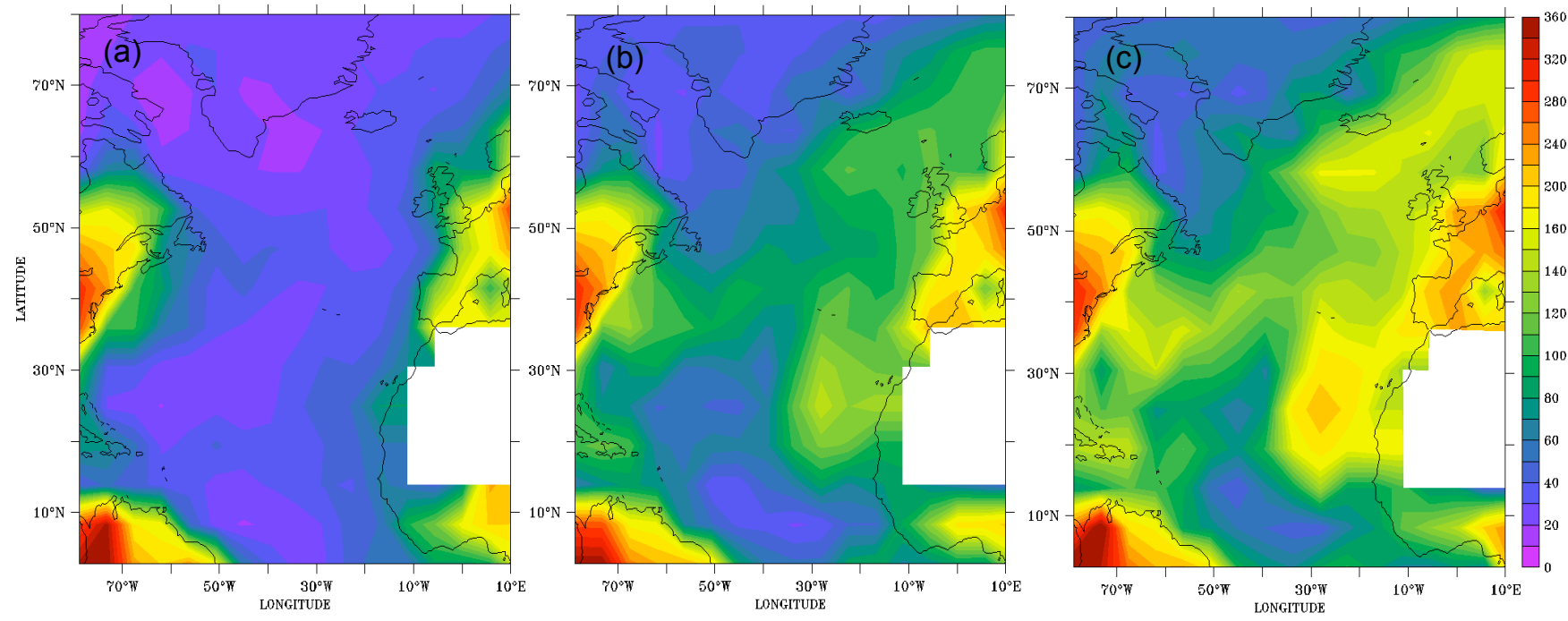

Fig. 3. Simulated cloud drop number concentration $\left(\mathrm{cm}^{-3}\right)$ averaged over June, July, August for (a) CTRL, (b) KeAe, and (c) $K x A x$. The model predicts no or little cloud occurrence over northern Africa.

while for the accumulation mode both internal and external mixtures yield results that are in relatively good agreement with the observations. Agreement within $20 \%$ between simulated and observed mass and chemical composition for both the Aitken and accumulation mode is obtained in $\mathrm{KeAi}$, KeAe and $K e A x$. The Aitken mode mass is larger than observed in $K x A i, K x A e$ and $K x A x$ but the agreement for the accumulation mode, that contains more than $90 \%$ of the fine mode aerosol mass, is also good.

The measurements of O'Dowd et al. (2004) show that a small but significant organic fraction of $\sim 3 \%$ is present in the coarse mode. The simulated transfer of mass from the Aitken and accumulation modes to the coarse mode, however, is insignificant. The production of atmospheric coarse mode organic matter thus appears to be directly coupled to the formation of sea salt aerosol, i.e. mechanical production of sea water droplets and subsequent evaporation of the water resulting in an internally mixed particle with inorganic and organic matter. This is in accordance with the observed similarities between marine aerosol organics and the organic composition of the sea water (Berg and Winchester, 1978). $\mathrm{KeAiCi}$ considers identical emissions as $\mathrm{KeAi}$ but an additional $25 \mathrm{Tg} \mathrm{C} / \mathrm{yr}$ of organics is mixed internally into the coarse mode. The coarse mode organic mass fraction then increases from $0 \%$ in CTRL to $1.5 \%$ in $\mathrm{KeAiCi}$, in better agreement but still smaller than the observations.

\section{2 $\mathrm{CDNC}$ and $R_{\mathrm{eff}}$}

Figures 3 and 4 illustrate the effect of marine aerosol organics on simulated cloud parameters. They show the summer distribution of CDNC and $R_{\text {eff }}$ over the North Atlantic Ocean simulated in CTRL, KeAe and KxAx. The model data are obtained by sampling the model domain as from a satellite, i.e. using the highest cloudy grid box from each model column, but at altitudes below $500 \mathrm{hPa}$ and with a cloud cover larger than $10 \%$. Over the North Atlantic ocean, however, large scale clouds are rare above $3000 \mathrm{~m}$ altitude, and most sampled clouds are located in or near the boundary layer. This is also where the largest impact from marine organics on CDNC is found (not shown). Model results show that the CDNC increase at altitudes below $1000 \mathrm{~m}$ is on average about threefold. The increase is significantly smaller at higher altitudes, about $10-20 \%$ at $2000 \mathrm{~m}$ altitude, reflecting a moderate transport out of the boundary layer. It must be noted that our model considers all organic aerosol to be primary. When SOA formation is explicitly represented it can be expected that the effect at higher altitudes may become larger due to transport of organic precursor gases out of the boundary layer. Figure 3 shows that CDNC increases between CTRL, KeAe and $K x A x$, especially between $30^{\circ} \mathrm{N}-$ $50^{\circ} \mathrm{N}$ and over the eastern North Atlantic. CDNC increases from 10-50 drops $\mathrm{cm}^{-3}$ in CTRL to values up to $140 \mathrm{~cm}^{-3}$ in KeAe and $200 \mathrm{~cm}^{-3}$ in $K x A x$. Over the remote North Atlantic, KeAe and $K x A x$ simulate an average CDNC of 90 $110 \mathrm{~cm}^{-3}$ and $100-150 \mathrm{~cm}^{-3}$, respectively. The model results are in good agreement with values of CDNC retrieved from MODIS. These are $90 \pm 27 \mathrm{~cm}^{-3}$ for the remote North Atlantic and up to $180 \mathrm{~cm}^{-3}$ for the eastern North Atlantic (Bennartz, 2007). In situ observations of CDNC in the North Atlantic marine atmosphere are reported by Leaitch et al. (1996), Borys et al. (1998) and Bower et al. (2000). Measured CDNC ranges between 50 and $400 \mathrm{~cm}^{-3}$ for relatively clean conditions. CDNC calculated with consideration of marine organics is in much better agreement also with these observations. 

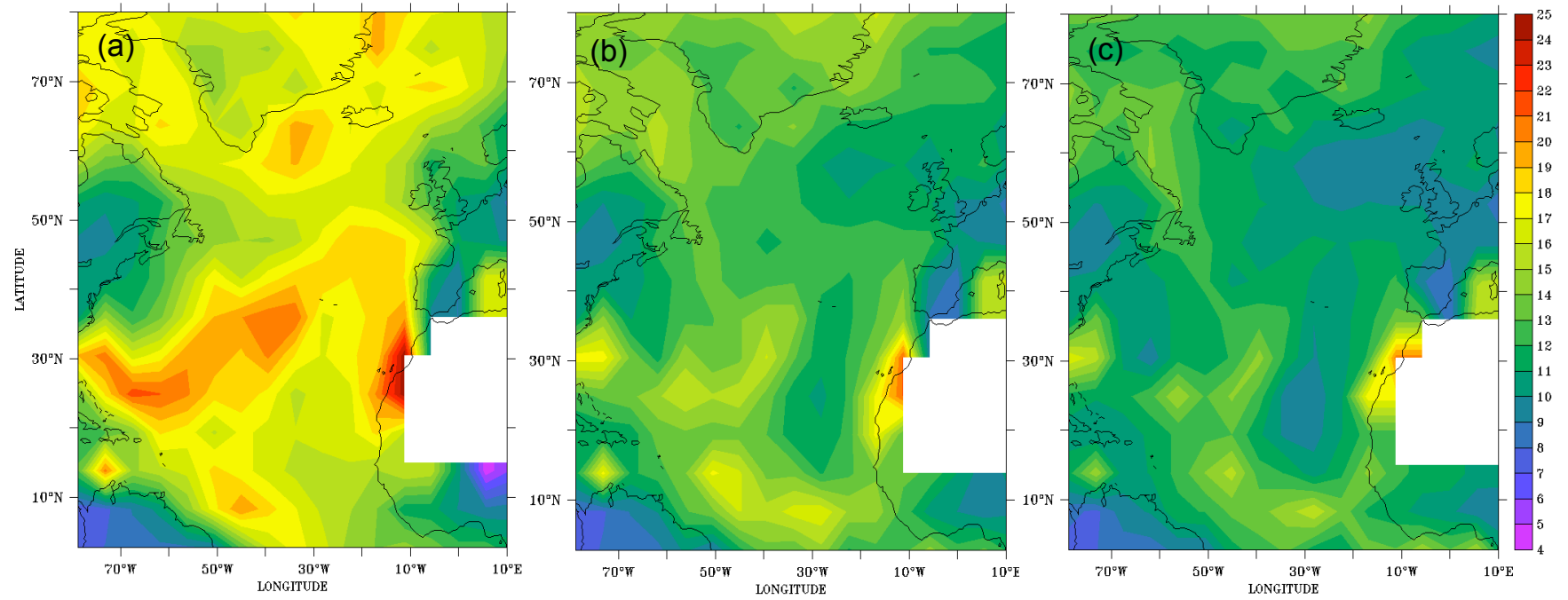

Fig. 4. Simulated cloud drop effective radius ( $\mu \mathrm{m})$ averaged over June, July, August for (a) CTRL, (b) $K e A e$, and (c) $K x A x$.

$R_{\text {eff }}$ decreases from $15-20 \mu \mathrm{m}$ in CTRL to $11-15 \mu \mathrm{m}$ in $K e A e$ and $10-14 \mu \mathrm{m}$ in $K x A x$ (Fig. 4). The results from $K e A e$ and $K x A x$ agree with remotely sensed cloud drop radii over the NH Atlantic Ocean reported by Han et al. (1994) of $10-16 \mu \mathrm{m}$. In CTRL $R_{\text {eff }}$ maximizes between $20^{\circ} \mathrm{N}$ and $40^{\circ} \mathrm{N}$. The maximum shifts to sub-tropical latitudes in KeAe and $K x A x$ because the effects of marine aerosol organics on $\mathrm{CDNC}$ and $R_{\text {eff }}$ are most pronounced north of $30^{\circ} \mathrm{N}$.

Figure 5 shows simulated CDNC in the remote marine boundary layer and averaged over JJA, and the contribution to CDNC from each mode. The data are from the region between $40^{\circ} \mathrm{N}-48^{\circ} \mathrm{N}$ and $40^{\circ} \mathrm{W}-20^{\circ} \mathrm{W}$, but results are qualitatively similar for other regions over the North Atlantic Ocean. In $A i$ the organic matter is mixed internally and CDNC is the same as in CTRL. In the external mixture simulations $A e$ and $A x$ more particles are present and become activated. When the concentration of accumulation mode particles is relatively small substantial activation of Aitken mode particles may take place, as seen in $K e$ and $K x$. Differences between $A e$ and $A x$, however, are more pronounced than between $K e$ and $K x$, illustrating that accumulation mode particles activate already at smaller supersaturations than Aitken mode particles. Finally, the organics added to the coarse mode in $\mathrm{KeAiCi}$ do not influence CDNC significantly.

\subsection{Comparison with ISCCP}

Figure 6 shows observed and simulated $R_{\text {eff }}$ for the northern $\left(40^{\circ} \mathrm{N}-48^{\circ} \mathrm{N}, 40^{\circ} \mathrm{W}-20^{\circ} \mathrm{W}\right)$ and the sub-tropical $\left(15^{\circ} \mathrm{N}-\right.$ $\left.25^{\circ} \mathrm{N}, 40^{\circ} \mathrm{W}-25^{\circ} \mathrm{W}\right) \mathrm{NH}$ Atlantic Ocean. Observed radii are from ISCCP (http://isccp.giss.nasa.gov/) and have an accuracy of a few $\mu \mathrm{m}$ (Han et al., 1994). The data display a seasonal variation of $R_{\text {eff }}$ with a summer maximum in the northern North Atlantic and a summer minimum in the equatorial North Atlantic.

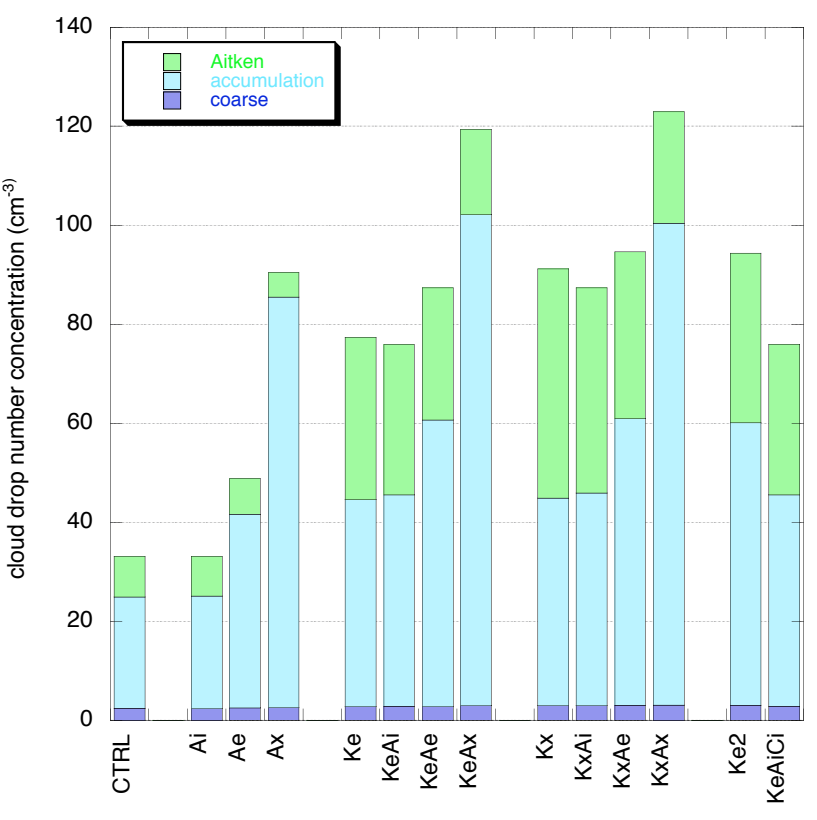

Fig. 5. Simulated cloud drop number concentration and contribution by the individual aerosol modes $\left(\mathrm{cm}^{-3}\right)$, averaged over June, July, August for the region $40^{\circ} \mathrm{N}-486 \circ \mathrm{N}, 40^{\circ} \mathrm{W}-20^{\circ} \mathrm{W}$.

In CTRL, $R_{\text {eff }}$ is larger than observed by 4 to $8 \mu \mathrm{m}$. When organics are added as an external mixture to the Aitken mode (Ke) $R_{\text {eff }}$ decreases significantly (Fig. 6a, b). Kx and $K e 2$ simulate higher concentrations of Aitken particles than $K e$ (Fig. 1) but perform only slightly better in terms of $R_{\text {eff }}$, which reflects that relatively high supersaturation values are required for activation of smaller Aitken particles. When the organic mass is added to the accumulation mode instead ( $A i$, $A e, A x)$ the simulated $R_{\text {eff }}$ displays a larger range (Fig. 6c, 
Northern Atlantic
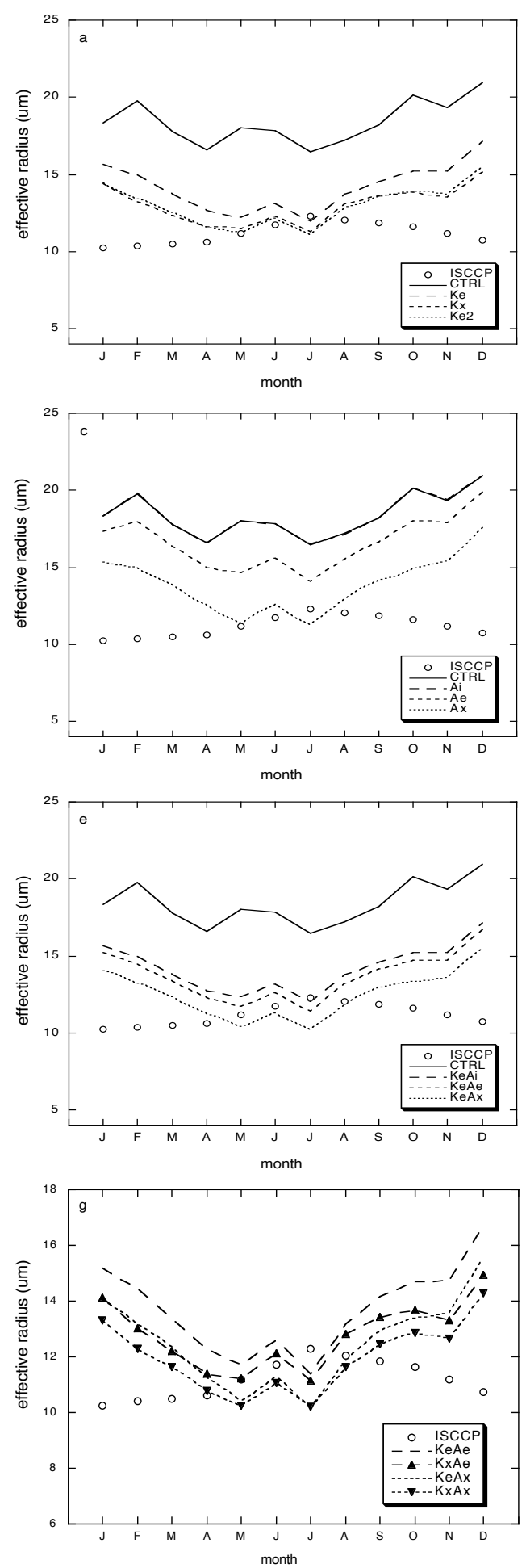

Equatorial Atlantic
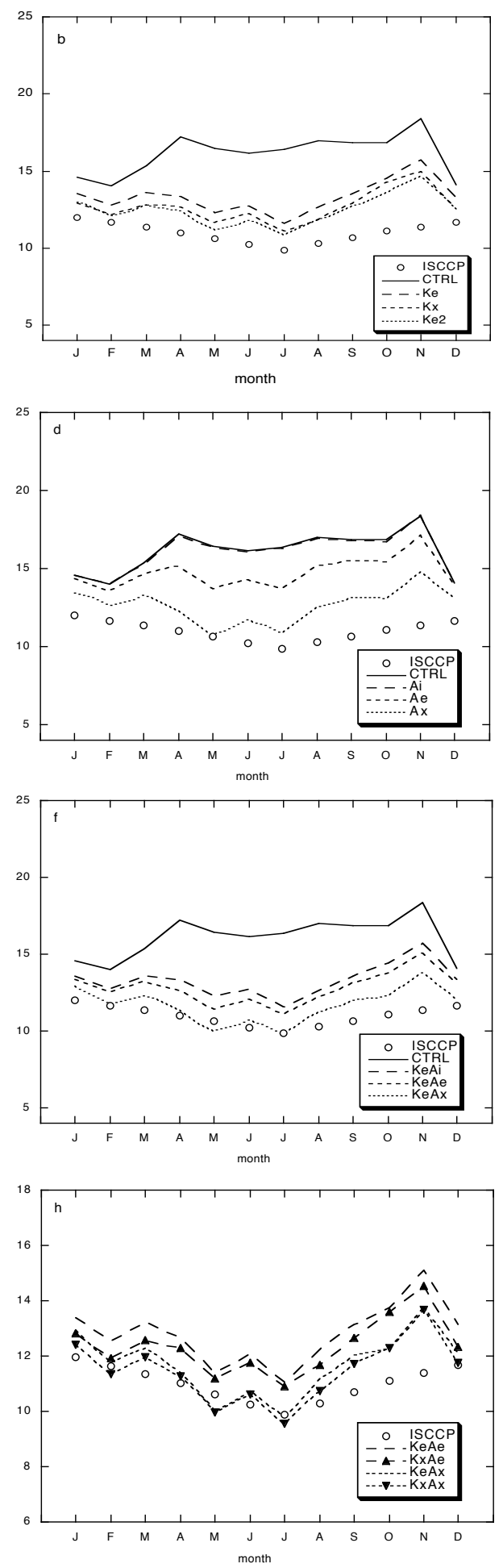

Fig. 6. Simulated monthly averaged cloud drop effective radius and ISCCP data for the regions $40^{\circ} \mathrm{N}-48^{\circ} \mathrm{N}, 40^{\circ} \mathrm{W}-20^{\circ} \mathrm{W}(\mathbf{a}, \mathbf{c}, \mathbf{e}, \mathbf{g})$ and $15^{\circ} \mathrm{N}-25^{\circ} \mathrm{N}, 40^{\circ} \mathrm{W}-25^{\circ} \mathrm{W}(\mathbf{b}, \mathbf{d}, \mathbf{g}, \mathbf{h})$. 
d). In $A i R_{\text {eff }}$ is the same as in CTRL, whereas $R_{\text {eff }}$ is closer to the observations in $A e$ and $A x$.

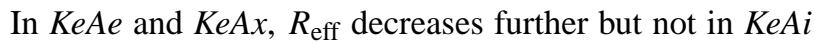
(Fig. 6e, f). Due to the relatively high supersaturation required to activate Aitken mode particles the $R_{\text {eff }}$ in KeAe does not differ significantly from KxAe in the summer (Fig. 6g, h) even though Aitken particle concentrations are much larger. However, in the winter in the northern North Atlantic, $R_{\text {eff }}$ in $K x A e$ is significantly smaller than in KeAe. The influence of the organic matter on the accumulation mode mass and number concentration is smaller than in summer and the Aitken mode contribution to CDNC becomes more prominent.

In the northern part of the North Atlantic the observations are characterized by a summer maximum while the model simulates a summer minimum and overestimates $R_{\text {eff }}$ in winter. We note that simulated $R_{\text {eff }}$ is also overestimated over the European continent in winter (Roelofs et al., 2006), and this may be partly caused by too small aerosol sulfate concentrations (Stier et al., 2005). Underestimation of sulfate concentrations in winter over Europe is a common feature of global simulations of the sulfur cycle (Roelofs et al., 1998). However, over the remote ocean sulfate concentrations are relatively small and probably not the main reason that $R_{\text {eff }}$ is overestimated. A plausible explanation may be that the typical size of new particles formed by condensation of non-volatile gases depends on temperature or supersaturation. We assume in our simulations the same critical nucleus size for new particle formation throughout the year, as is also assumed for sulfuric acid (Wilson et al., 2001). However, the saturated vapor pressure for semi-volatile organic gases, which depends on temperature, is smaller in winter than in summer and the ambient supersaturation is higher, and this results in a smaller critical size for nucleation (e.g. Girshick and Chiu, 1990). This effect is suggested in the observations, specifically the seasonal variation of the Aitken mode mean diameter, from $0.03 \mu \mathrm{m}$ in winter to $0.06 \mu \mathrm{m}$ in summer (Yoon et al., 2007; their Fig. 3). The number concentration of freshly formed particles per unit condensed mass may therefore be larger in winter. As a result the size distribution of aerosol organic matter may resemble KeAe or KeAx in the summer and to $K x A e$ or $K x A x$ in winter.

For the sub-tropical North Atlantic region the average simulated $R_{\text {eff }}$ is also significantly improved when marine aerosol organics are considered, and the simulated seasonality is also in much better agreement with observations.

\subsection{Southern Hemisphere}

Although our study focuses on the NH Atlantic Ocean region, we will briefly discuss the model representativity over the SH. Based on remotely sensed $R_{\text {eff }}$ near the island of South Georgia east of south America, a location with a strong plankton bloom seasonality, Meskhidze and Nenes (2006) argue that aerosol organic matter originating from isoprene emissions from plankton significantly affects marine cloud characteristics. They inferred a possible concentration range for SOA from isoprene from $5 \mathrm{ng} \mathrm{m}^{-3}$ in air relatively unaffected by the plankton bloom to $230 \mathrm{ng} \mathrm{m}^{-3}$ when the isoprene flux into the atmosphere is relatively large. As a result,

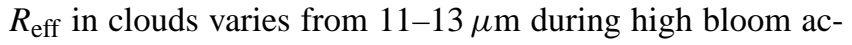
tivity in summer to $14-16 \mu \mathrm{m}$ during low bloom activity in winter. Simulations $K e A i$ and $K e A e(K x A i$ and $K x A e)$ calculate monthly averaged $R_{\text {eff }}$ of $12-13 \mu \mathrm{m}(11-12 \mu \mathrm{m})$ in November and $14-15 \mu \mathrm{m}$ in June, months with high and low bloom activity, respectively. In CTRL, without marine organics, the simulated $R_{\text {eff }}$ during high bloom activity is larger, $14-17 \mu \mathrm{m}$. The simulated monthly averaged organic aerosol mass in summer near South Georgia, of the order of $200 \mathrm{ng} \mathrm{m}^{-3}$ in $\mathrm{KeAiCi}$, is close to the estimate by Meskhidze and Nenes (2006) for the period with high bloom activity. This concentration is also in agreement with the measurements of marine organic aerosol near Amsterdam Island of $200-300 \mathrm{ng} / \mathrm{m}^{3}$ (average value: $220 \mathrm{ng} / \mathrm{m}^{3}$ ) for the bloom period (J. Sciare, personal communication).

For the region west of Tasmania, Boers et al. (2006) used MODIS data to derive a seasonal cycle of $R_{\text {eff }}$ from 14$16 \mu \mathrm{m}$ in summer to $21-24 \mu \mathrm{m}$ in winter. The simulated $R_{\text {eff }}$ west of Tasmania in winter ranges around $20 \mu \mathrm{m}$ in summer and $23 \mu \mathrm{m}$ in CTRL, but is significantly decreased due to the influence of organics in the sensitivity simulations. For example, in $\mathrm{KeAiCi} R_{\text {eff }}$ near Tasmania is $14 \mu \mathrm{m}$ in summer and $19 \mu \mathrm{m}$ in winter, respectively, in better agreement with the observations.

\section{Conclusions and discussion}

We used the global aerosol-climate model ECHAM5-HAM to investigate the potential influence of marine aerosol organics on simulated aerosol and cloud characteristics. Without these organics the model underestimates the aerosol organic mass and $\mathrm{CCN}$ concentrations in the marine atmosphere, and overestimates $R_{\text {eff }}$ in marine clouds. By introducing organic matter in the Aitken and accumulation modes, separately or combined, in different amounts and mixing states, we investigate if the simulated and observed aerosol mass, aerosol chemical composition and cloud drop size can be brought in better agreement with observations. We used a relatively simple top-down approach where different organic yields and mixing states are prescribed for the relevant aerosol modes. Measurements of O'Dowd et al. (2004) for the aerosol mass and composition, ISCCP for cloud drop size and other remotely sensed and in situ observations were used to evaluate these emission scenarios.

We discussed in Sect. 3 that the seasonality and spatial distribution of the emission of the aerosol organic matter and of DMS may be similar, but a more detailed validation of emissions and organic aerosol formation is required to confirm this. This must also involve precursor gases and the contributions of primary and secondary aerosol formation, and it 
requires a detailed calculation of emissions, chemical processes and gas-to-particle conversion of which our model is not capable yet.

For a global amount of $50 \mathrm{Tg} \mathrm{C} / \mathrm{yr}$ of marine organic aerosol, equally distributed over the Aitken and accumulation modes, the study showed a reasonable agreement between simulated and observed aerosol organic burdens over the North Atlantic ocean and in other marine regions. Another $25 \mathrm{Tg} / \mathrm{yr}$, but possibly more, may be attributed to the coarse mode. Different pathways of adding organics to the aerosol phase may be involved, with different effects on particle number concentration. Adding organic matter to the fine mode aerosol in an external mixing state increases the amount of cloud condensation nuclei in the marine atmosphere, leading to a larger CDNC, up to a factor of three, and smaller $R_{\text {eff }}$ in marine clouds. Relatively good agreement between simulation results and observations is found when about $30 \%-50 \%$, or $25-40 \mathrm{Tg} \mathrm{C} / \mathrm{yr}$, of marine organic aerosol originates from secondary aerosol formation, for which isoprene is a potential precursor (e.g. Meshkidze and Nenes, 2006), and is deposited in the Aitken and accumulation modes. Results indicate that the critical size of newly formed particles varies with season, with more and smaller particles in winter than in summer. The remaining $35-50 \mathrm{Tg}$ C/yr is probably emitted as primary particles, originating from the organic microfilm at the ocean surface or from dissolved or undissolved organic matter in the ocean water.

The total marine aerosol organic production found in our study, $75 \mathrm{Tg} \mathrm{C} / \mathrm{yr}$, can be linked to a carbon uptake and release by the marine biomass of $100 \mathrm{Gt} / \mathrm{yr}$ (Schlesinger, 1997). In comparison, estimates of organic aerosol production from terrestrial vegetation range between several tens and several hundreds Tg C/yr (Kanakidou et al., 2005; Goldstein and Galbally, 2007), and these are associated with a carbon uptake and release of $120 \mathrm{Gt} / \mathrm{yr}$. The numbers for the terrestrial and marine biospheres appear consistent, indicating that our result is plausible.

We emphasize that other processes and approximations in the model may affect the representativity of simulated CDNC and $R_{\text {eff }}$ to some extent, such as the cloud activation parameterization and uncertainties in the calculated updraft velocity, inaccurate transport patterns associated with the relatively coarse resolution, and errors in the emission and size distribution of sea salt. In view of all uncertainties we tentatively estimate the uncertainty in the marine aerosol organic production to be in the order of $25 \mathrm{Tg} / \mathrm{yr}$.

Our simulations indicate that organics emitted from the ocean surface may significantly contribute also to the seasonality of marine cloud optical properties. This makes the organic fraction of the marine aerosol an important contributor to the optical properties of the natural background atmosphere. Representation of aerosol organics originating from the ocean surface in aerosol-climate studies may result in a considerable decrease of the estimated indirect forcing due to anthropogenic aerosol in marine regions compared to current estimates.

Acknowledgements. We thank the Stichting Nationale Computerfaciliteiten (NCF) for the use of supercomputer facilities, with financial support from the Nederlandse Organisatie voor Wetenschappelijk Onderzoek (NWO). We acknowledge the use of the visualization and analysis package Ferret (http://www.ferret.noaa.gov).

Edited by: R. von Glasow

\section{References}

Andreae, M. O., Jones, C. D., and Cox, P. M.: Strong presentday cooling implies a hot future, Nature, 435, 1187-1190, doi:10.1038/nature03671, 2005.

Bennartz, R.: Global assessment of marine boundary layer cloud droplet umber concentration from satellite, J. Geophys. Res., 112, D02201, doi:10.1029/2006JD007547, 2007.

Berg, W. W. and Winchester, J. W.: Aerosol chemistry of the marine atmosphere, in: Chemical Oceanography, Vol. 7, edited by: Riley, J. P. and Chester, R., pp. 173-231, Academic Press, London, 1978.

Boers, R., Acaterra, J. R., and Gras, J. L.: Satellite monitoring of the first indirect effect: Retrieval of the droplet concentration of water clouds, J. Geophys. Res., 111, D22208, doi:10.1029/2005JD006838, 2006.

Borys, R. D., Lowenthal, D. H., Wetzel, M. A., Herrera, F., Gonzales, A., and Harris, J.: Chemical and microphysical properties of marine stratiform cloud in the North Atlantic, J. Geophys. Res., 103(D17), 22 073-22 085, 1998.

Bower, K. N., Choularton, T. W., Gallagher, M. W., et al.: ACE-2 HILLCLOUD. An overview of the ACE-2 ground-based cloud experiment, Tellus, 52B, 750-778, 2000.

Cavalli, F., Facchini, C., Decesari, S., Mircea, M., Emblico, L., Fuzzi, S., Ceburnis, D., Yoon, Y. J., O’Dowd, C. D., Putaud, J. P., and Dell'Acqua, A.: Advances in characterization of sizeresolved organic matter in marine aerosol in the North Atlantic, J. Geophys. Res., 109, D24215, doi:10.1029/2004JD005137, 2004.

Claeys, M., Graham, B., Vas, G., Wang, W., Vermeylen, R., Pashynska, V., Cafmeyer, J., Guyon, P., Andreae, M. O., Aetaxo, P., and Maenhout, W.: Formation of secondary organic aerosols through photooxidation of isoprene, Science, 303, 1173-1176, doi:10.1126/science.1092805, 2004.

Dusek, U., Frank, G. P., Hildebrandt, L., Curtius, J., Schneider, J., Walter, S., Chand, D., Drewnick, F., Hings, S., Jung, D., Borrmann, S., and Andreae, M. O.: Size Matters More Than Chemistry for Cloud-Nucleating Ability of Aerosol Particles, Science, 312, 1375-1378, doi:10.1126/science.1125261, 2006.

Fizgerald, J. W.: Marine aerosols: a review, Atmos. Environ. A, 25, 533-545, 1991.

Girshick, S. L. and Chiu, C.-P.: Kinetic nucleation theory: A new expression for the rate of homogeneous nucleation from an ideal supersaturated vapor, J. Chem. Phys., 93, 1273-1277, 1990.

Goldstein, A. H. and Galbally, I. E.: Known and unexplored organic constituents in the Earth's atmosphere, Environ. Sci. Technol., 1515-1521, 2007. 
Han, Q., Rossow, W. B., and Lacis, A. A.: Near-global survey of effective droplet radii in liquid water clouds using ISCCP data, J. Climate, 7, 465-497, 1994.

Hänel, G.: The role of aerosol properties during the condensational stage of cloud: a reinvestigation of numerics and microphysics, Beitr. Phys. Atmosph., 60, 321-339, 1987.

Heintzenberg, J., Covert, D. C., and van Dingenen, R.: Size distribution and chemical composition of marine aerosols: a review, Tellus 52B, 1104-1122, 2000.

Hoffman, E. J. and Duce, R. A.: Factors influencing the organic carbon content of atmospheric sea salt particles: A laboratory study, J. Geophys. Res., 81, 3667-3670, 1976.

Jacobson, M. C., Hansson, H. C., Noone, K. J., and Charlson, R. J.: Organic atmospheric aerosols: Review and state of the science, Rev. Geophys., 38, 267-294, 2000.

Kanakidou, M., Seinfeld, J. H., Pandis, S. N., et al.: Organic aerosol and global climate modeling: a review, Atmos. Chem. Phys., 5, 1053-1123, 2005, http://www.atmos-chem-phys.net/5/1053/2005/.

Kentarchos, A. S., Roelofs, G. J., and Lelieveld, J.: Simulation of extratropical synoptic scale stratosphere-troposphere exchange using a coupled chemistry-GCM: Sensitivity to horizontal resolution, J. Atmos. Sci., 57, 2824-2838, 2000.

Kerminen, V. M.: Relative roles of secondary sulfate and organics in atmospheric cloud condensation nuclei production, J. Geophys. Res., 106, 17 321-17 333, 2001.

Kulmala, M., Pirjola, L., and Mäkelä, J.: Stable sulphate clusters as a source of new atmospheric particles, Nature, 404, 66-69, 2000.

Leaitch, W. R., Banic, C. M., Isaac, G. A., Couture, M. D., Liu, P. S., Gultepe, I., and Li, S. M.: Physical and chemical observations in marine stratus during the 1993 North Atlantic Regional Experiment: Factors controlling cloud droplet number concentrations, J. Geophys. Res., 101, 29 123-29 135, 1996.

Lohmann, U. and Roeckner, E.: Design and performance of a new cloud microphysics scheme developed for the ECHAM4 general circulation model, Clim. Dynam., 12, 557-572, 1996.

Lohmann, U. and Lesins, G.: Stronger constraints on the anthropogenic indirect aerosol effect, Science, 298, 5595, 1012-1015, doi: 10.1126/science.1075405, 2002.

Lohmann, U. and Feichter, J.: Global indirect aerosol effects: a review, Atmos. Chem. Phys., 5, 715-737, 2005, http://www.atmos-chem-phys.net/5/715/2005/.

Meshkidze, N. and Nenes, A.: Phytoplankton and cloudiness in the southern ocean, Science, 314, 1419-1423, doi:10.1126/science.1131779, 2006.

O'Dowd, C. D., Smith, M. H., Consterdine, I. E., and Lowe, J. A.: Marine aerosol, sea-salt, and the marine sulphur cycle: a short review, Atmos. Environ., 31, 73-80, 1997.

O’Dowd, C. D., Facchini, M. C., Cavalli, F., Ceburnis, D., Mircea, M., Decesari, S., Fuzzi, S., Yoon, Y. J., and Putaud, J.-P.: Biogenically-driven organic contribution to marine aerosol, Nature, 431, 676-680, 2004.
Penner, J. E., Andreae, M. O., Annegarn, H., et al.: Aerosols, their direct and indirect effects, in: Climate Change 2001: The Scientific Basis, edited by: Houghton, J. T., Ding, Y., Griggs, D. J., et al., 289-348, Cambridge University Press, Cambridge, 2001.

Roelofs, G. J., Ganzeveld, L. G., and Lelieveld, J.: Simulation of global sulfate distribution and the influence on effective cloud drop radii with a coupled photochemistry-sulfur cycle model, Tellus, 50B, 224-242, 1998.

Roelofs, G. J., Stier, P., Feichter, J., Vignati, E., and Wilson, J.: Aerosol activation and cloud processing in the global aerosolclimate model ECHAM5-HAM, Atmos. Chem. Phys., 6, 23892399, 2006, http://www.atmos-chem-phys.net/6/2389/2006/.

Schlesinger, W. H.: Biogeochemistry: An Analysis of Global Change, 2nd Edition. Academic Press, San Diego, USA, 587 pp., 1997.

Shaw, S. L., Chisholm, S. W., and Prinn, R. G.: Isoprene production by Prochlorococcus, a marine cyanobacterium, and other phytoplankton, Marine Chemistry, 80, 227-245, 2003.

Sinha, V., Williams, J., Meyerhöfer, M., Riebesell, U., Paulino, A. I., and Larse, A.: Air-sea fluxes of methanol, acetone, acetaldehyde, isoprene and DMS from a Norwegian fjord following a phytoplankton bloom in a mesocosm experiment, Atmos. Chem. Phys., 7, 739-755, 2007, http://www.atmos-chem-phys.net/7/739/2007/.

Stier, P., Feichter, J., Kinne, S., Kloster, S., Vignati, E., Wilson, J., Ganzeveld, L., Tegen, I., Werner, M., Balkanski, Y., Schulz, M., and Boucher, O.: The aerosol-climate model ECHAM5-HAM, Atmos. Chem. Phys., 1125-1156, 2005.

Textor, C., Schulz, M., Guibert, S., et al.: Analysis and quantification of the diversities of aerosol life cycles within AeroCom, Atmos. Chem. Phys., 6, 1777-1813, 2006, http://www.atmos-chem-phys.net/6/1777/2006/.

Vignati, E., Wilson, J., and Stier, P.: M7: An efficient sizeresolved aerosol microphysics module for large-scale aerosol transport models, J. Geophys. Res., 109(D22), D22202, doi:10.1029/2003JD004485, 2004.

Wilson, J., Cuvelier, C., and Raes, F.: A modeling study of global mixed aerosol fields, J. Geophys. Res., 106, 34 081-34 108, 2001.

Yokouchi, Y., Li, H. J., Machida, T., Aoki, S., and Akimoto, H.: Isoprene in the marine boundary layer (Southeast Asian Sea, eastern Indian Ocean, and Southern Ocean): comparison with dimethyl sulfide and bromoform, J. Geophys. Res., 104, 8067-8076, 1999.

Yoon, Y. J., Ceburnis, D., Cavalli, F., Jourdan, O., Putaud, J. P., Facchini, M. C., Decesari, S., Fuzzi, S., Sellegri, K., Jennings, S. G., and O'Dowd, C. D.: Seasonal characteristics of the physicochemical properties of North Atlantic marine atmospheric aerosols, J. Geophys. Res., 112, D04206, doi:10.1029/2005JD007044, 2007. 